\title{
Short simulation exercises to improve emergency department nurses self-efficacy for initial disaster management: Controlled before and after study
}

Carl-Oscar J onson, J enny Pettersson, J onas Rybing, Heléne Nilsson and Erik Prytz

The self-archived version of this journal article is available at Linköping University Electronic Press:

http:// urn.kb.se/ resolve?urn=urn:nbn:se:liu:diva- 139548

N.B.: When citing this work, cite the original publication.

J onson, C., Pettersson, J ., Rybing, J., Nilsson, H., Prytz, E., (2017), Short simulation exercises to improve emergency department nurses self-efficacy for initial disaster management: Controlled before and after study, Nurse Education Today, 55, 20-25. https:// dx.doi.org/ 10.1016/j.nedt.2017.04.020

Original publication available at:

https://dx.doi.org/10.1016/j.nedt.2017.04.020

Copyright: Elsevier

http://www.elsevier.com/

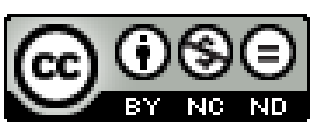


Short simulation exercises to improve emergency department nurses' self-

2 efficacy for initial disaster management: Controlled before and after study.

3

4

5

6

7

8

9

10

Jonson C-O, Pettersson J, Rybing J, Nilsson H, Prytz E.

Nurse Educ Today. Elsevier; 2017;55(March):20-5.

Available at http://linkinghub.elsevier.com/retrieve/pii/S0260691717300965 

improve emergency department

13 nurses' self-efficacy for initial disaster

14 management: controlled before and

15 after study

Abstract

Introduction: Head nurses at emergency departments often assume responsibility for managing the initial response to a major incident, and to create surge capacity. Training is essential to enable these nurses to perform an effective disaster response. Evaluating the effects of such training is however complicated as real skill only can

21 be demonstrated during a real major incident. Self-efficacy has been proposed as an 22 alternative measure of training effectiveness.

23 Purpose: The aim of this study was to examine if short, small-scale computer-based simulation exercises could improve head emergency nurses' general and specific selfefficacy and initial incident management skills.

Method: A within-group pretest-posttest design was used to examine 13 head nurses' general and specific self-efficacy before and after an intervention consisting of three short computer based simulation exercises during a 1-hour session. Management skills were assessed using the computer simulation tool DigEmergo.

30 Results: The exercises increased the head nurses' general self-efficacy but not their specific self-efficacy. After completing the first two exercises they also exhibited improved management skills as indicated by shorter time to treatment for both trauma

33 and in-hospital patients.

34 Conclusion: This study indicates that short computer based simulation exercises 35 provide opportunities for head nurses to improve management skills and increase their 36 general self-efficacy. 
Key words: management, mass casualty incident, nurses, simulation training, surge capacity

\section{Introduction}

Following a major incident (MI) with multiple casualties there is an immediate

need to increase the capacity to triage, treat and logistically manage the high influx of victims, particularly at geographically close trauma hospitals that will have little time to react before patients reach the emergency department (ED). This increase in capacity is generally referred to as surge capacity, and is created by managing resources and patient flow (Barbisch \& Koenig, 2006). Overcrowded EDs and a constant lack of hospital beds are common in many hospitals, and this directly influences disaster preparedness by reducing surge capacity (Abir, 2013). Even a moderate-sized incident can affect the health care system to the extent that a small expansion in capacity requires activation of the disaster plan and optimal use of every resource (Bradt et al., 2009; Khorram et al., 2009; Lennqvist, 2012).

In the ED, nurses often assume responsibility for the management of emergency response and function in leadership roles, managing and coordinating health care and caregivers. ED coordinator nurses must be prepared to respond as local leaders, adapt nursing practices, and to coordinate with hospital command, medical officers and other staff to minimize adverse medical outcome caused by a MI (Gebbie \& Qureshi, 2002; Jennings-Sanders, Frisch, \& Wing, 2005; Smith, Farra, Dempsey, \& Arms, 2015). In the Swedish healthcare system it is typically the head emergency nurse that receives the initial MI alert at the ED and initiate the hospital response according to the disaster response plan (Nilsson \& Kristiansson, 2015). 
of the healthcare system to handle MIs depends on appropriate planning with welltrained and practised organizations. There is a growing body of evidence that shows that training is essential for effective disaster response and for a rapid and correct decision-making process in the stress and chaos of the moment (Auf den Heide, 2006; Brannan, White, \& Bezanson, 2008; Pattillo, 2006; Smith, 2015; Watters, 2015; Wilkerson, 2008). MIs are rare events, which means that daily activities alone cannot be relied on to provide the necessary experience needed to manage such large-scale events. Simulation-based training is one method that has been increasingly used within emergency and disaster management to achieve the required knowledge, skills and experience. Simulation exercises can be an effective training method for teaching emergency management by creating opportunities for repetitive practice and facilitating different learning strategies in a safe and educational environment (Olson, standard operation procedures to achieve an effective medical response to an MI. Studies have shown that simulation-based training can enhance clinical learning, confidence, motivation to learn, clinical performance, critical thinking, and selfefficacy (Brannan et al., 2008; Okuadet et al., 2009; Pattillo, 2006; Smith, et al., 2015;

83 Stefanidis et al., 2012; Watters, 2015; Wilkerson et al., 2008). Some studies have also used simulations to successfully increase trainees' knowledge of disaster 
medicine and basic competence in performing mass casualty triage (Ingrassia et al., 2014; Nilsson et al., 2015).

It is important to ensure that simulation exercises really do improve the trainees' ability to perform accurately in an MI. In a literature review specifically on the efficiency of hospital staff MI training, Hsu et al. (2004) stated that there was insufficient evidence to support firm conclusions on the efficiency of any one specific training method. They concluded that more attention should be directed to evaluating the efficiency of MI training activities. One problem, however, is that the actual results of a MI training intervention only can be seen during a real MI, which are rare events. There are several confounding variables, such as time elapsed since training or staff turnover, that reduces the ability to draw firm conclusions about the efficiency of previous training. Instead, the typical measure used is training performance, with the assumption that increased skill at performing in the simulated scenario will translate to the real situation (Ford \& Weissbein, 1997; Grossman \& Salas, 2011). A simulator that correctly and efficiently enables learners to gain new knowledge is said to exhibit a high level of educational validity, which reflects both the learners understanding of the simulation and the real-world applicability of knowledge and skills learnt (Feinstein \& Cannon, 2002). Another way to look at the effect of a training intervention is to measure the participants' self-efficacy. Self-efficacy can function as an indirect measure of the impact of training to improve skills in health care and is one way to understand the potential impact of an educational intervention on later clinical practice (Hsu, 2015; Artino, 2015).

Self-efficacy is the extent to which an individual believes him or herself to be capable of performing a specific behaviour in a specific situation (Bandura, 1997). 
109 Specific self-efficacy is task-related and means the extent to which the individual

110 claims to be capable of performing a specific task. Self-efficacy can be affected in

111 four ways according to Bandura (1997): mastery experiences, social modelling, social

112 persuasion and psychological responses. Master responses means that experience

113 from previous similar situations increases self-efficacy. Social modelling considers

114 that by observing others successfully performing a task, the individual believes that

115 also he or she can do the same. Social persuasion means that an individual can be

116 verbally convinced that he or she has the capability to perform a specific behaviour in

117 a specific situation. The last source of self-efficacy, according to Bandura, is the

118 individual's own response and reaction to the situation. Mood, emotional status and

119 stress can affect an individual's self-efficacy. Anxiety, for example, can create a

120 physical discomfort that reduces self-efficacy (Bandura, 1997). Individuals with high

121 self-efficacy use more effective ways to solve problems because they believe in their

122 ability to handle the situation. Self-efficacy can thus be used as an indicator of the

123 ability to carry out a clinical behaviour (Cant \& Cooper, 2010).

$124 \quad$ Simulated disaster exercises that allow participants to practice nursing

125 leadership skills can increase their working knowledge and perceived self-efficacy

126 related to emergency management through mastery experiences. Training can also

127 enhance self-efficacy in clinical situations and nurses' perceived abilities relating to

128 leadership and management of clinical scenarios (Watters, 2015; Smith, 2015). One

129 of the major effects of simulated exercises may be to develop self-confidence in

130 performance (Cant \& Cooper, 2010). It is also the case that in an educational

131 situation, individuals with high self-efficacy learn more and perform better than those 
132 with low self-efficacy (Bandura, 1997; Wood and Bandura, 1989). Thus, training to

133 improve self-efficacy can be beneficial for subsequent training sessions.

134 The National Board of Health in Sweden recommends frequent and regular

135 education, training and exercises as one way to enable head emergency nurses to deal

136 with the managerial activities associated with MIs (SOSFS2013:22 §6-7). In order for

137 such training to be realised there is an interest to explore small-scale training

138 interventions with short time demands and minimal disruption on day-to-day

139 healthcare operations. In line with the recommendations of Hsu et al. (2004) and

140 Artino (2015), the efficiency of such training interventions should be investigated, for

141 example by measuring its effect on trainee self-efficacy. The aim of the current study

142 was therefore to examine if short, small-scale computer-based simulation exercises,

143 using a prototype training system called DigEmergo, would improve head emergency

144 nurses' self-efficacy and MI management skills. The study was named Simulation-

145 based Training of Resource Management in the Emergency Room (STORMER).

$146 \quad$ Method

148 design, in which participants' self-efficacy was measured using questionnaires before

149 and after partaking in three simulated surge capacity scenarios. An a priori power

150 analysis indicated a minimum participant sample of 12 to detect a large effect (Cohen,

151 1988)

Participants

153

13 registered head nurses at an emergency department at a small town hospital

154 in Sweden participated in the study. The nurses who were invited to participate were 
155 the individuals appointed to receive and manage the initial surge at the ED in the case

156 of an MI. Two of the participants were men and 11 were women. The age of the

157 participants varied from 31 to 63 years $(M=41.5, S D=9.8)$ and their $n u r s i n g$

158 experience varied from 2 to 42 years $(\mathrm{M}=13.9, \mathrm{SD}=11.7)$. Years as a registered

159 nurse in an $E D$ varied from 1 to 15 years $(\mathrm{M}=5.5, \mathrm{SD}=4.6)$, and experience as a

160 head nurse varied from 1 to 10 years $(\mathrm{M}=4.0, \mathrm{SD}=3.2)$.

Measures

162

The participants were asked to complete pre- and post-test questionnaires

163 about their general and specific self-efficacy as well as their perception of their ability

164 to organize and manage the initial response to an MI. General self-efficacy was

165 measured using a validated version of the General Self-Efficacy Scale translated into

166 Swedish (Löve, Moore, \& Hensing, 2012). In this questionnaire the participants rated

16710 statements using a 5-point Likert scale ranging from 1 (strongly disagree) to 5

168 (strongly agree) with a higher score indicating a greater level of self-efficacy. Specific

169 self-efficacy was measured by six statements based on performance indicators for

170 medical response at an ED developed by Nilsson (2012). The statements reflected the

171 participants' estimated self-belief about their ability to cope with the task as an initial

172 disaster manager at an ED. The indicators reflected specific management skills by

173 considering the time taken to convey the alert to ED management and staff, time

174 taken to create an adequate number of trauma and medical teams, time taken to

175 activate the hospitals' disaster plan and time taken to establish contact with the

176 hospital management. The six statements used the same 5-point Likert scale format as

177 the general self-efficacy questionnaire. 
179 during each scenario and the time to treatment of in-hospital patients and trauma

180 patients were saved in the DigEmergo database. Time to treatment was defined as the

181 time, in seconds, from a patient being introduced on the screen to the time when the

182 patient was assigned a staff resource (e.g., nurse or doctor).

183

\section{Procedure}

Prior to the test the participants were only aware that the whole procedure would take 60 minutes, comprise three scenarios and that their management performance would be measured. Each session started by having the participant read and sign the written informed consent form, followed by a demographics questionnaire and the self-efficacy pre-test questionnaire. The participant then performed a 5-minute training session on how to use DigEmergo after which they were asked to manage three consecutive, 10 minutes long, simulated MI scenarios. The scenarios (a bus accident, a fire at an elderly care unit, and a train crash) were all designed to clearly overwhelm the hospital's resources but to otherwise provide a similar level of challenge. All scenarios featured a simulated ED with 25 beds divided among 4 emergency trauma rooms and 12 ordinary examination rooms. Each scenario was initiated by the presentation of an alert from the Emergency Call Centre (ECC) with preliminary, and therefore incomplete, information about the MI. The number of critically injured patients allocated to the hospital was always seven, with two arriving within the 10 minutes of the scenario time. The number of in-hospital ED patients and available staff varied from 9 to 19 and 14 to 23 , respectively, to provide scenario variation. The scenario order was balanced across participants to prevent order 
201 effects. Each participant was asked to perform initial management in the scenario by

202 handling the patient flow exactly as they would in real life. For each scenario the

203 instructor verbally introduced a series of interventions, such as new information from

204 the on-scene medical commander. The interventions were the same for all participants

205 and followed a predetermined schedule. Immediately after the third scenario, the

206 participants completed the post-test questionnaire. The entire session lasted 60

207 minutes.

\section{Equipment}

The DigEmergo simulation system used in this study was developed in a

210 collaboration between the Centre of Teaching and Research in Disaster Medicine and

211 Traumatology (KMC) and Linköping University based on the existing training system

212 Emergo Train System (Rybing et al., 2015, 2016). The participants worked with

213 DigEmergo on a 65" touchscreen with 1920x1080 resolution running on standard

214 workstation Windows 7 PC. The ED and trauma patients were visualized on the

215 screen according to the preprogramed standardized scenarios. By touching the screen,

216 the participants could move the patients and staff around the ED, triage patients,

217 initiate treatments, and transport patients to a number of destinations, e.g. a hospital

218 ward or home. An earlier version of this software running on a 77" SmartBoard

219 interactive whiteboard surface is shown in Figure 1. The DigEmergo system was

220 moved to the actual ED at which the study took place and installed in a closed room

221 adjacent to the clinical space. 
All local, regional, and national guidelines for ethical permission were

followed. According to these guidelines no formal ethical approval process was required, but ethical consideration was still given with regard to the need for consent, the information requirement, confidentiality obligations and utilization requirement

229 (World Medical Association, 2008). Before the simulation session, the study was 230 explained to all participants individually and they were informed that participation in 231 the study was voluntary and they had the option to discontinue at any time. All 232 participants gave written informed consent for participation. In addition, participants 233 were assured that participation or non-participation would in no way compromise 234 their work situation at the ED. The participants attended the study either before or 235 after their normal shift so as not to compromise ED staffing. Permission to carry out 236 the study at the ED was given by the ED head manager.

\section{Statistical analysis}

One-way paired samples t-tests with a significance level of 0.05 were used to compare the pre- and post-test scores of self-efficacy. The t-test family of statistical

240 tests are normally considered robust against violations of non-normal distributions

241 (Maxwell, 2004). The predicted direction of effect was that general and specific self242 efficacy would increase from pre- to post-test. One-way paired samples t-tests were 243 also used to compare management skill differences between the first and the third 244 scenario. Again the predicted effect was that management skill would improve from 245 the first to the third scenario. 95\% confidence intervals of the difference were used as 
246 effect size measure. All the statistical analyses were performed using Statistical

247 Package for Social Science, SPSS, V.22.

\section{Results}

All 13 study participant head nurses successfully completed each test session.

\section{Self-efficacy}

The one-way paired $t$-test on general self-efficacy showed that the mean post-

252 test level was significantly higher than the pre-test $t(12)=3.105, p=.0046,95 \% \mathrm{CI}$

$253[1.2,6.9]$. The mean general self-efficacy score was $35.7(\mathrm{SD}=5.06)$ for the pre-test 254 and $39.8(\mathrm{SD}=4.1)$ for the post-test, see Figure 2a.

255 There was no significant difference in the mean specific self-efficacy score $256 t(12)=0.969, p=0.175,95 \%$ CI $[-0.96,2.49]$. The mean specific self-efficacy score 257 was $22.6(\mathrm{SD}=3.88)$ at the pre-test and $23.3(\mathrm{SD}=3.1)$ at the post-test, see Figure $2582 b$.

[Insert Figure 2a and $\mathrm{b}$ here]

\section{Management skills}

The paired sample $t$-test showed a significant decrease in time to treatment of

263 trauma patients, i.e. those patients that arrived from the accident scene, between the 264 first and third exercise session $t(12)=2.654, p=0.010,95 \%$ CI $[-25.36,-2.49]$. The 265 mean time to treatment of trauma patient was 24 seconds $(S D=18)$ in the first 266 exercise and 10 seconds $(\mathrm{SD}=5)$ in the third, see Figure $3 \mathrm{a}$. 
267 There was also a significant decrease in time to treatment of in-hospital patients, i.e.

268 those patients already in the hospital when the accident occurred, between the first

269 and third scenario, $t(12)=2.159, p=0.025,95 \%$ CI $[-116.7,-0.53]$. The mean time to

270 treatment of in-hospital patient in the first exercise was 164 seconds (SD = 67), and in

271 the third exercise 106 seconds $(\mathrm{SD}=56)$, see Figure $3 b$.

272

273

274

275

276

277

278

279

280

281

282

283

[Insert Figure 3a and $\mathrm{b}$ here]

The paired $t$-test on the number patients that were given care showed no significant difference between first simulation to the third, $t(12)=1.7, p=0.057,95 \%$ CI $[-0.67,5.44]$. The mean number of patients taken care of in the first exercise was $9.0(\mathrm{SD}=2.9)$ and in the third exercise it was $11.4(\mathrm{SD}=3.6)$, see Figure 4.

[Insert figure 4 here]

[Insert tables here]

\section{Discussion}

The current study found that the short, computer-based simulation exercises using DigEmergo significantly increased head nurses' general self-efficacy and management skill as measured by time to treatment for both trauma and in-hospital patients. These findings imply that this training method could potentially be one way to enhance the confidence that the nurses have concerning task performance, their perseverance when obstacles are met, and their resilience in facing adverse situations. 
Improving the head nurses' general self-efficacy through simulation exercises could make them more prepared to make decisions in a stressful situation and thereby manage the acute incoming surge in the ED during a MI more effectively. emergency head nurses is one way to understand the potential impact of an educational intervention on later clinical practice. However, it is important not to overestimate the association between reported self-efficacy and abilities. According to Bandura (1997), expectations alone do not produce a desired performance. However, given the appropriate skills and motivation, efficacy expectations are a major determinant of a person's choice of activities. In a training context, measurable

300 performance indicators should therefore also be used in addition to self-efficacy 301 measurements.

In the current study, this was done by using the data on time to treatment of in-

303 hospital patients and trauma patients and the number of patients that received care.

304 The results showed no statistically significant increase in the number of patients that

305 received care, but did show a significant decrease in time to treatment of trauma 306 patients and of in-hospital patient from the first session to the third. There are two 307 basic ways to interpret this: 1) that the trainees have improved in their general skill of 308 managing surge which will translate to more efficient handling during a real MI, or 2) 309 that the trainees have improved specifically in their skill at running the simulator only 310 and will be no better at handling a real MI. This is a question of transfer-of-training 311 and simulation validity, i.e. if the skills trained in the simulator will transfer from the 312 training context to the real context. It is not possible from this study alone to conclude 313 anything about the simulation validity. Further studies are needed specifically aimed 
314 at addressing the question of simulation validity. If the simulation, DigEmergo, can be

315 shown to train the specific skills required during a real MI it can be said to have high

316 validity. Together with the current study that show skill improvement, the combined

317 results would demonstrate the system's usefulness as a training method for emergency

318 medicine management skills.

319 The current study found no support for an increase in specific self-efficacy

320 using this training method. This could be because the specific self-efficacy instrument

321 used has not been independently tested and validated, and may thus not be measuring

322 the correct underlying variables. There is currently no validated instrument to

323 measure self-efficacy specifically related to the context of managing a MI. Another

324 plausible explanation is that the national quality indicators for MI medical response

325 that the instrument was based on (Nilsson et al., 2010) concerned tasks or skills that

326 were not included and measured in the DigEmergo simulator. For instance, there is no

327 "hospital management" to contact in the simulator, which was one of the statements

328 in the specific self-efficacy questionnaire. Thus, the participants may not have been

329 trained on these management skills, which would explain the lack of change in

330 specific self-efficacy. In a study by Fry (2014) the emergency nurses' general self-

331 efficacy was reported as high, although specific practical tasks, such as handling high

332 patients numbers, caused this to fluctuate. This indicates the importance of identifying

333 factors that affect self-efficacy and to include these factors in simulation exercises

334 with the purpose of training and enhancing self-efficacy. Additional studies of other

335 training methods should be conducted to validate a specific self-efficacy instrument

336 for emergency medicine management, and to test other training strategies for

337 improving nurses' specific self-efficacy. 

scenarios used were about 10 minutes in length and run at near-real time. This

340 simulates only a small part of the initial hospital management of an MI, as the effects

341 might impact the hospitals' ability to deliver healthcare for days. The short scenario

342 time was used based on the purpose of the study, which was to investigate the use of

343 short simulation-based exercises on head nurse's self-efficacy and management skill.

344 The scenarios used in the current study could be complemented with equally short

345 scenarios that capture a different time period of the MI management process, e.g. the

346 second day, the start of the first hour immediately after the event, or other

347 departments. Longer sessions could also be used to capture performance over an

348 extended time; however, this creates a higher threshold for participation as it takes

349 more time from the nurses' day-to-day activities. A benefit of longer scenarios,

350 however, is the possibility to measure more variables, such as performance indicators

351 for decision-making and patient flow variables such as length of stay and patient

352 outcome.

353 It should also be noted that the effects of the training intervention were

354 measured immediately post-training. A longitudinal study is required to investigate

355 how well this effect holds over time. Burstein (2006) stated improving specific

356 functions in the health care system requires repeated training sessions because

357 knowledge that is not frequently used is forgotten. The use of simulation exercises is

358 valuable because it allows the nurses to repeatedly participate rare and critical events

359 in a safe environment with no direct risk to patients (Farra, 2015). The use of

360 computer simulations such as DigEmergo provides the opportunity to organize small

361 simulations with minimal impact on the hospital's day-to-day activities and can 
362 facilitate frequent training of incident management skills. The use of computer-

363 simulated exercises also has the advantage that the data from the simulations can be

364 analysed directly after the exercise and the results are available for immediate

365 debriefing (Burstein, 2006).

366

\section{Conclusions}

This study found support for the use of short computer-based simulation

exercises as a method to train head nurses to improve management skills and increase their self-efficacy. Simulation-based training is known to increase skill and selfefficacy in a range of domains, and this work provides additional support for the use of short and small-scale simulation-based training as a mean to create opportunities for clinical staff to engage in such training with little impact on day-to-day activities.

\section{References}

Abir, M., Davis, M. M., Sankar, P., Wong, A. C., \& Wang, S. C. (2013). Design of a model to predict surge capacity bottlenecks for burn mass casualties at a large academic medical center Prehospital and Disaster Medicine, 28(1), 23-32.

Artino, A. R., Jr, Dong, T., DeZee, K. J., Gilliland, W. R., Waechter, D. M., Cruess, D. F., et al. (2012). Development and initial validation of a survey to assess students' self-efficacy in medical school. Military Medicine, 177(9 Suppl), 3137.

Auf der Heide, E. (2006). The importance of evidence-based disaster planning. Annals of Emergency Medicine, 47(1), 34-49.

Bandura, A. (1997). Self-efficacy: The exercise of control. Basingstoke: W. H. Freeman.

Barbisch, D. F., \& Koenig, K. L. (2006). Understanding surge capacity: Essential elements Academic Emergency Medicine : Official Journal of the Society for Academic Emergency Medicine, 13(11), 1098-1102. 
Bradt, D. A., Aitken, P., Fitzgerald, G., Swift, R., O'Reilly, G., \& Bartley, B. (2009). Emergency department surge capacity: Recommendations of the Australasian surge strategy working group. Academic Emergency Medicine, 16(12), 13501358.

Brannan, J. D., White, A., \& Bezanson, J. L. (2008). Simulator effects on cognitive skills and confidence levels. The Journal of Nursing Education, 47(11), 495-500.

Burstein, J. L. (2006). The myths of disaster education. Annals of Emergency Medicine, 47(1), 50-52.

Cant, R. P., \& Cooper, S. J. (2010). Simulation-based learning in nurse education: Systematic review. Journal of Advanced Nursing, 66(1), 3-15.

Cohen J. (1988). Statistical Power Analysis for the Behavioral Sciences. New York, NY: Routledge Academic

Farra, S. L., Miller, E. T., \& Hodgson, E. (2015). Virtual reality disaster training: Translation to practice. Nurse Education in Practice, 15(1), 53-57.

Feinstein, A. H., \& Cannon, H. M. (2002). Constructs of Simulation Evaluation. Simulation \& Gaming, 33(4), 425-440.

Ford, J. K., \& Weissbein, D. A. (1997). Transfer of training: An updated review and analysis. Performance Improvement Quarterly, 10(2), 22-41.

Fry, M., \& MacGregor, C. (2014). Confidence and impact on clinical decisionmaking and behaviour in the emergency department. Australasian Emergency Nursing Journal, 17(3), 91-97.

Gebbie, K. M., \& Qureshi, K. (2002). Emergency and disaster preparedness: Core competencies for nurses. The American Journal of Nursing, 102(1), 46-51.

Grossman, R., \& Salas, E. (2011). The transfer of training: what really matters. International Journal of Training and Development, 15(2), 103-120.

Hsu, E. B., Jenckes, M. W., Catlett, C. L., Robinson, K. a, Feuerstein, C., Cosgrove, S. E., ... Bass, E. B. (2004). Effectiveness of hospital staff mass-casualty incident training methods: a systematic literature review. Prehospital and Disaster Medicine, 19(3), 191-9.

Hsu, L. L., Chang, W. H., \& Hsieh, S. I. (2015). The effects of scenario-based simulation course training on nurses' communication competence and selfefficacy: A randomized controlled trial. Journal of Professional Nursing, 31(1), $37-49$. 
Ingrassia, P. L., Ragazzoni, L., Tengattini, M., Carenzo, L., \& Della Corte, F. (2014). Nationwide program of education for undergraduates in the field of disaster medicine: development of a core curriculum centered on blended learning and simulation tools. Prehospital and Disaster Medicine, 29(5), 508-15.

Jennings-Sanders, A., Frisch, N., \& Wing, S. (2005). Nursing students' perceptions about disaster nursing. Disaster Management and Response, 3(3), 80-85.

Khorram-Manesh, A., Hedelin, A., \& Ortenwall, P. (2009). Hospital-related incidents; causes and its impact on disaster preparedness and prehospital organisations. Scandinavian Journal of Trauma, Resuscitation and Emergency Medicine, 17, 26-7241-17-26.

Lennqvist, K. (2015). Development and evalutation of a new simulation model for education, research and quality assurance in disaster medicine. Medical dissertation. Institute of Clicial Sciences at Sahlgrenska Academy University of Gothenburg. ISBN: 978-91-628-9336-1

Lennqvist, S. (2012). Medcial resonse to major incidents and disasters. A practical guide for medical staff. Berlin Heidelberg: Springer-Verlag.

Löve, J., Moore, C. D., \& Hensing, G. (2012). Validation of the Swedish translation of the general self-efficacy scale. Quality of Life Research, 21(7), 1249-1253.

Maxwell, S.E., \& Delaney, H. D. (2004). Designing experiments and analyzing data: A model comparison perspective $\left(2^{\text {nd }}\right.$ Ed). Psychology Press: New York, NY.

Nilsson, A., Åslund, K., Lampi, M., Nilsson, H. \& Jonson, C.-O. (2015). Improved and sustained triage skills in firemen after a short training intervention. Scandinavian Journal of Trauma, Resuscitation and Emergency Medicine, 23(81),

Nilsson, H., \& Kristiansson, T. (2015). Katastrofmedicinsk beredskap: Att leda sjukvård på ett särskilt sätt (1. uppl. ed.). Lund: Studentlitteratur.

Nilsson, H., Vikström, T., Rüter, A. (2010). Quality control in disaster medicine training - Initial regional medical command and control as an example. American Journal of Disaster Medicine, 5(1), 35-40

Okuda, Y., Bryson, E. O., DeMaria, S., Jr, Jacobson, L., Quinones, J., Shen, B., et al. (2009). The utility of simulation in medical education: What is the evidence? The Mount Sinai Journal of Medicine, New York, 76(4), 330-343.

Olson, D. K., Hoeppner, M. M., Scaletta, K., Peck, M., \& Newkirk, R. (2012). Games, simulations, and learning in emergency preparedness: A review of the literature. American Journal of Disaster Medicine, 7(2), 145-154. 
Pattillo, M. (2006). Teaching Disaster Nursing Response Using Simulations. Clinical Simulation in Nursing, 2(2), e49-e51.

Rybing, J., Nilsson, H., Jonson, C.-O., \& Bang, M. (2015). Studying distributed cognition of simulation-based team training with DiCoT. Ergonomics, 59(3), 423-434.

Jonas Rybing, Erik Prytz, Johan Hornwall1,2, Heléne Nilsson, Carl-Oscar Jonson, \& Magnus Bang (2016). Designing a Digital Medical Management Training Simulator Using Distributed Cognition Theory. Simulation \& Gaming, 48(1). 122.

Smith, S., Farra, S., Dempsey, A., \& Arms, D. (2015). Preparing nursing students for leadership using a disaster-related simulation. Nurse educator, 40(4), 212-216.

Socialstyrelsen, Katastrofmedicinsk beredskap [eng. Disaster medicine preparedness], SOSFS2013:22 §6-7 (2013).

Stefanidis, D., Scerbo, M. W., Montero, P. N., Acker, C. E., \& Smith, W. D. (2012). Simulator Training to Automaticity Leads to Improved Skill Transfer Compared With Traditional Proficiency-Based Training. Annals of Surgery, 255(1), 30-37.

Watters, C., Reedy, G., Ross, A., Morgan, N. J., Handslip, R., \& Jaye, P. (2015). Does interprofessional simulation increase self-efficacy: A comparative study. BMJ Open, 5(1)

World Medical Association (2013). WMA declaration of Helsinki - ethical principles for medical research involving human subjects. Retrieved 28/06/2016 from http://www.wma.net/en/30publications/10policies/b3/

Wilkerson, W., Avstreih, D., Gruppen, L., Beier, K. P., \& Woolliscroft, J. (2008). Using immersive simulation for training first responders for mass casualty incidents Academic Emergency Medicine, 15(11), 1152-1159.

Wood, R., \& Bandura, A. (1989). Impact of conceptions of ability on self-regulatory mechanisms and complex decision making. Journal of Personality and Social Psychology, 56(3), 407-415. 


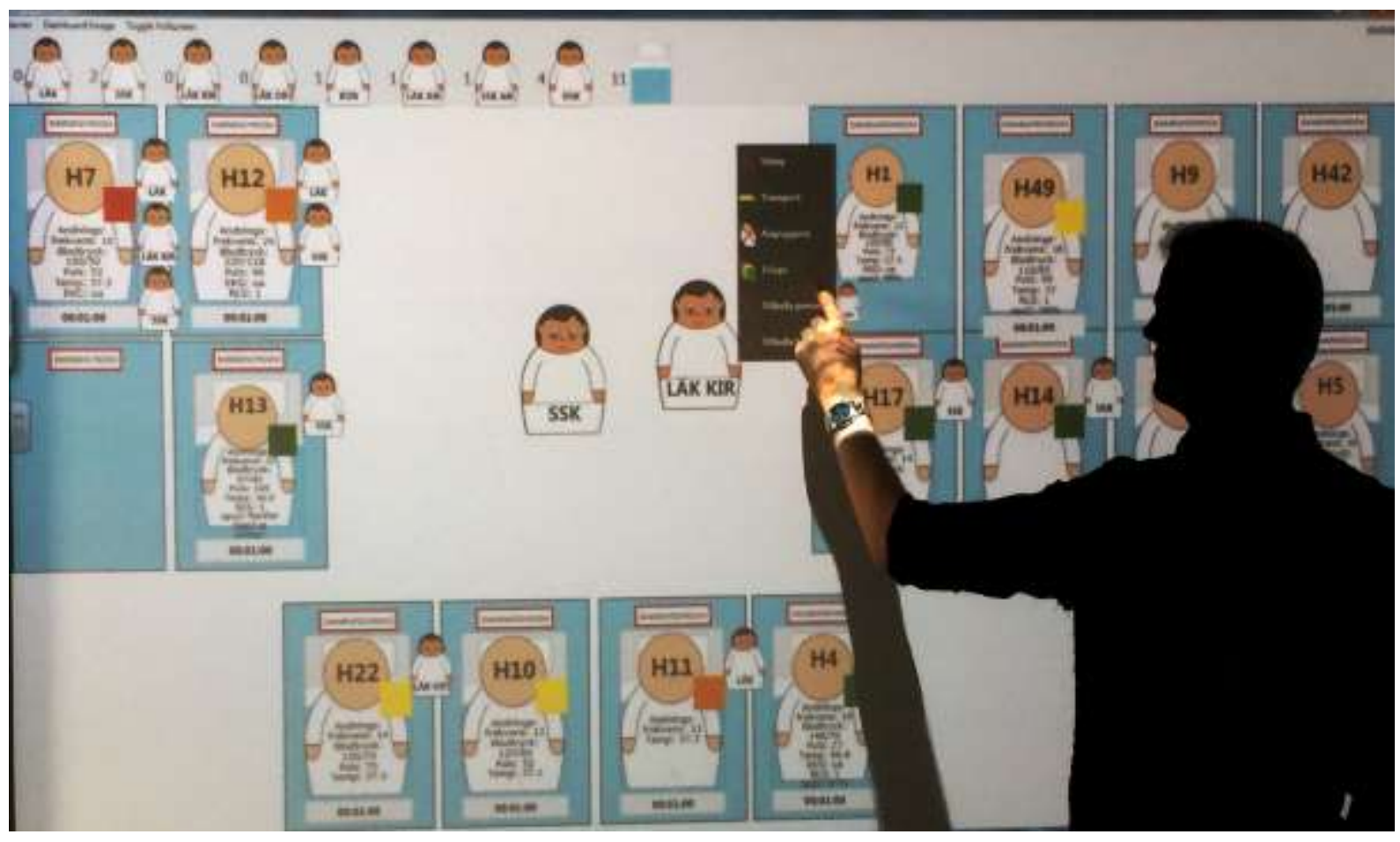

489

491 SmartBoard.

492
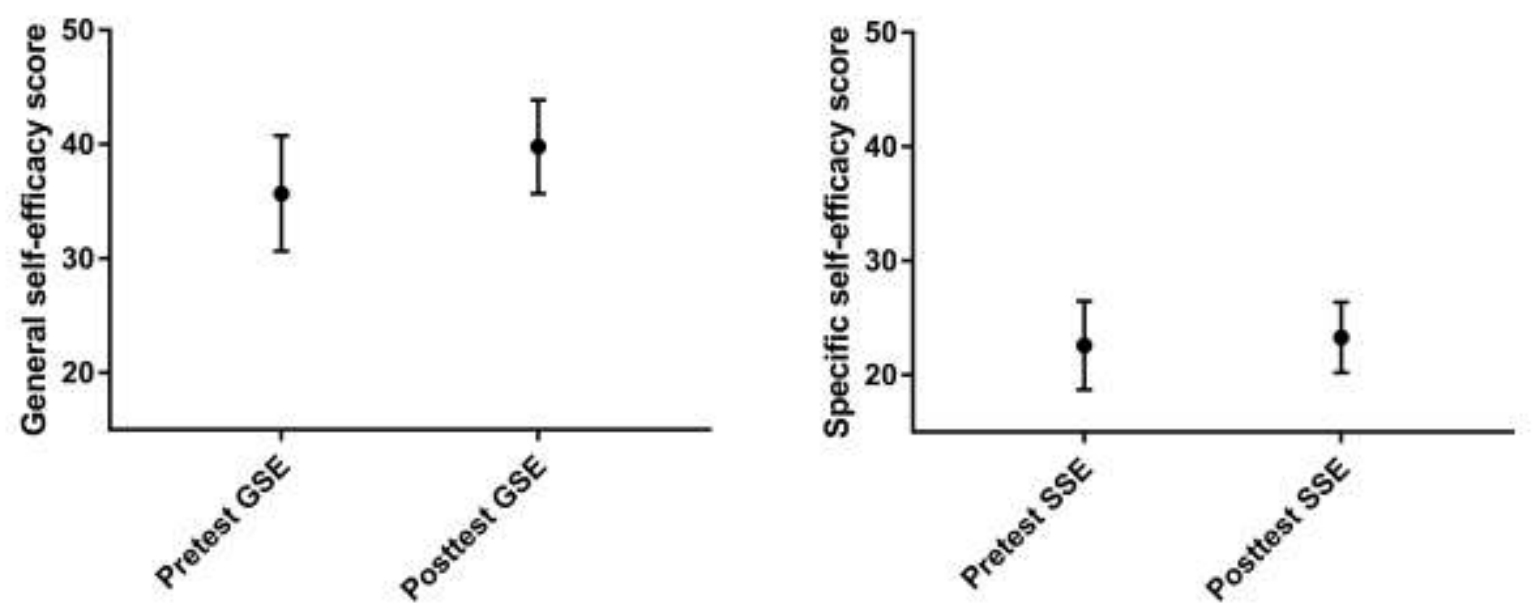
495 the three simulation exercises.

497 the three simulation exercises.

498

499
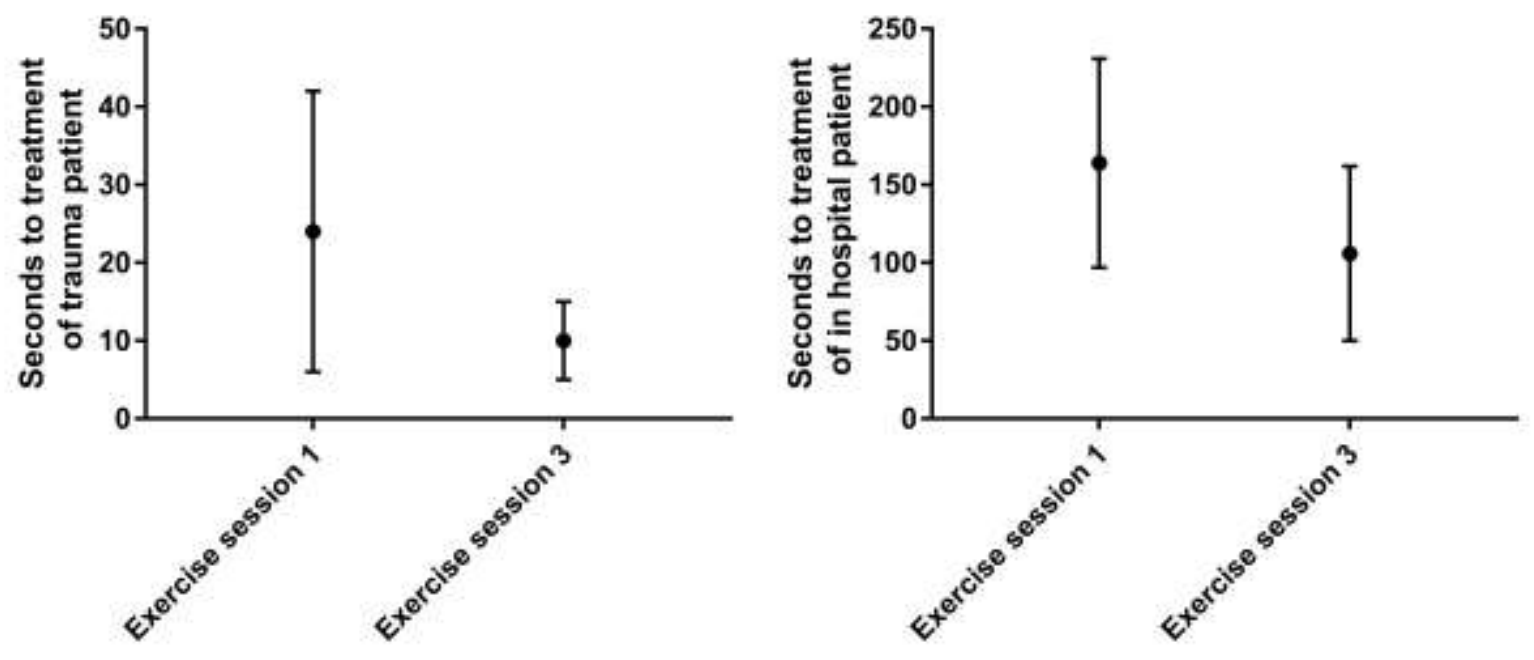

Figure 3a. Mean and SD of time from trauma patient arriving in the ED to

502 head nurse assigned staff to start the treatment of the patient in the first and third

503 exercise.

505 treating in-hospital patient in the first and third exercise.

506 


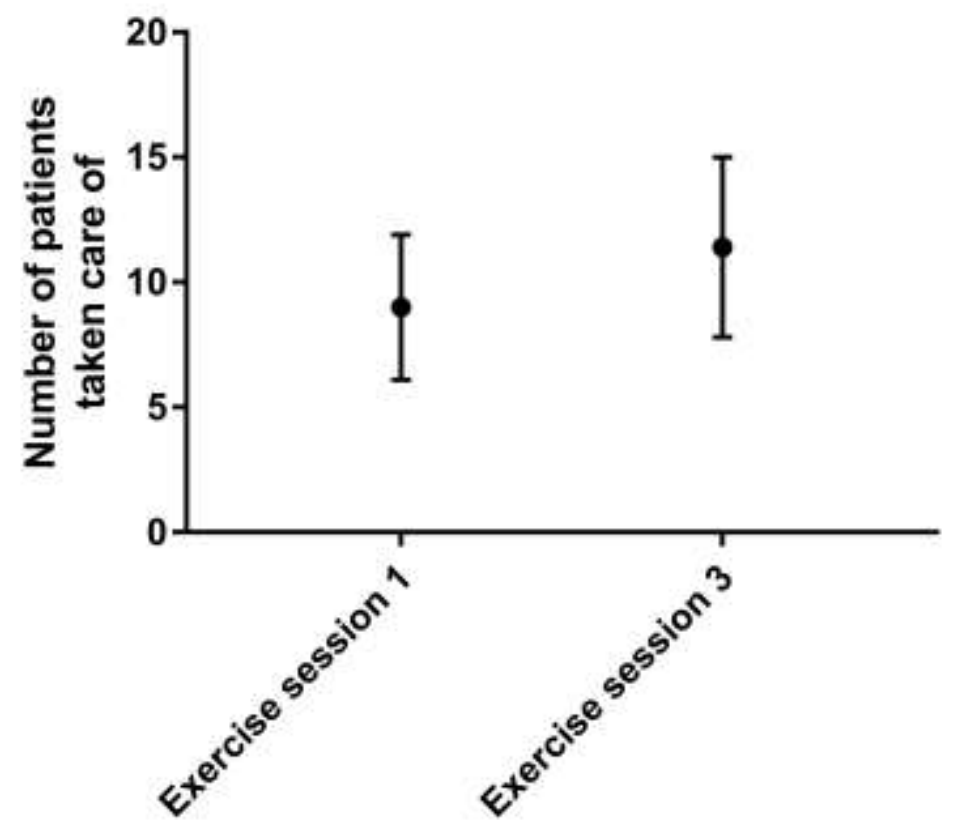

508

509 Figure 4. Mean and SD for number of patients taken care by the head nurse

510 during the first and the third exercise.

511

512

513

514 